\title{
Nasal and extra nasal MRSA colonization in hemodialysis patients of north-west of Iran
}

\author{
Fatemeh Ravanbakhsh Ghavghani ${ }^{1}$, Leila Rahbarnia ${ }^{1,2^{*}}$ (D), Behrooz Naghili ${ }^{1}$, Alireza Dehnad ${ }^{1,2,3}$, Ahad Bazmani ${ }^{1}$, \\ Mojtaba Varshochi ${ }^{1}$ and Mohammad Hossein Ghaffari Agdam ${ }^{4}$
}

\begin{abstract}
Objectives: Methicillin resistant Staphylococcus (S.) aureus colonization is one of the main causes of serious infections in hemodialysis patients. This cross-sectional study was performed to examine prevalence of MRSA colonization and evaluation of risk factors in hemodialysis patients. A total of 560 swab samples from nasal, the skin around catheter and throat were collected from 231 hemodialysis patients in Tabriz. The standard biochemical tests were used for identification of $S$. aureus isolates. Antimicrobial susceptibility profile was determined against 11 antibiotics by the disk diffusion method. Phenotypic test of $S$. aureus was performed using novobiocin $30 \mu \mathrm{g} / \mathrm{disc}$, and methicillin sensitivity test was performed by cefoxitin $30 \mathrm{\mu g} / \mathrm{disc}$.

Results: Overall, 50.65\% (118/231) hemodialysis patients were positive for S. aureus which 34.93\% (80/231) of patients were MRSA carriage. The MRSA colonization in patients with a catheter (44.06\%) was more than individuals utilizing a fistula (24.57\%, $p=0.030)$. Among sampling sites, the highest MRSA was related to nasal samples (30.70\%, $p<0.00001)$. Extra nasal colonization of $S$. aureus was observed in $12.71 \%$ patients. The highest rates of resistance were observed against ampicillin (93.98\%) and the highest sensitivity was against linezolid antibiotic (5.42\%). These findings highlight the necessity of prophylaxis against $S$. aureus in individuals under dialysis.
\end{abstract}

Keywords: S. aureus, MRSA colonization, Hemodialysis patients

\section{Introduction}

The prevalence of bacterial infections is one of the main reasons of mortality in hemodialysis patients. In fact, the weakened immune system and nature of dialysis devices predispose hemodialysis patients for infection. Based on recent reports, Staphylococcus (S.) aureus is the most prevalent bacterial infection in hemodialysis individuals ranging from minor skin infections to serious infections including bacteremia, osteomyelitis, necrotizing pneumonia, infective endocarditis, and toxic shock syndrome (TSS) [1]. It is capable of colonization in the different sites of body such axillary, perineal and nasal (nasal carriage of $S$. aureus) [2,3].

The nasal carriage of $S$. aureus is not often the main cause of infection however it can act as a reservoir for

\footnotetext{
*Correspondence: le.rahbarnia@gmail.com

1 Infectious and Tropical Diseases Research Center, Tabriz University of Medical Sciences, P.O.Box; 5163639888, Tabriz, Iran

Full list of author information is available at the end of the article
}

subsequent infections in individuals colonized with this pathogen $[4,5]$.

At present, the emergence of antibiotic resistant $S$. aureus strains known as methicillin-resistant $S$. aureus (MRSA) has become a serious menace in hospital and community settings. The MRSA infections are mainly associated with increasing morbidity and mortality and length of hospital stay especially in individuals with cancer, HIV, diabetes, rheumatoid arthritis and patients undergoing dialysis [1].

The origin of $S$. aureus infections in dialysis patients is mostly related to $S$. aureus nasal carriage. This microorganism is transmitted from the nasal reservoir to the hands and skin, and then to the access. So, the prevention of colonization of $S$. aureus can be an effective method to infection control in hemodialysis patients. This study was aimed to examine prevalence of MRSA colonization in hemodialysis patients as a main cause of infection and mortality in hemodialysis population.

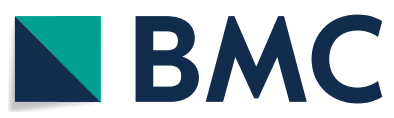

C The Author(s) 2019. This article is distributed under the terms of the Creative Commons Attribution 4.0 International License (http://creativecommons.org/licenses/by/4.0/), which permits unrestricted use, distribution, and reproduction in any medium, provided you give appropriate credit to the original author(s) and the source, provide a link to the Creative Commons license, and indicate if changes were made. The Creative Commons Public Domain Dedication waiver (http://creativecommons.org/ publicdomain/zero/1.0/) applies to the data made available in this article, unless otherwise stated. 


\section{Main text \\ Methods \\ Sample collection}

The swab samples were collected from hemodialysis patients referred to the Imam Reza hospital of Tabriz, Iran from July 6, 2018 to August 6, 2018. The samples were obtained from three different sites including nasal, throat and skin around the catheter. Patients' clinical data including gender, age and clinical conditions were recorded before samples collection. The relationship between $S$. aureus carriage and clinical conditions of hemodialysis patients such as hypertension, diabetes mellitus, glomerulonephritis, lupus, familial Mediterranean fever, polycystic kidney, cardiovascular, pulmonary infections and length of hospitalization, the effect of risk factors such smoking was also examined. The procedures followed were according to the ethical standards of the committee on human experimentation of our institution.

\section{Bacteria identification}

The samples were cultured in selective media (Manitol Salt agar and blood agar media) and incubated overnight at $37{ }^{\circ} \mathrm{C}$. The $S$. aureus isolates were identified based on conventional microbiological and biochemical tests (Gram-staining, colony morphology, coagulase test (coagulase was positive for S. aureus) and catalase test [6].

\section{Antimicrobial susceptibility testing}

The susceptibility pattern of isolates to various antibiotics was determined by Kirby Bauer disk diffusion testing based on the Clinical Laboratory Standards Institute (CLSI) guidelines [7]. Antibiotic disks used were as follow: oxacillin $(1 \mu \mathrm{g})$, mupirocin $(10 \mu \mathrm{g})$, rifampicin $(5 \mu \mathrm{g})$, erythromycin $(15 \mu \mathrm{g})$, clindamycin $(2 \mu \mathrm{g})$, minocycline $(30 \mu \mathrm{g})$, linezolid $(30 \mu \mathrm{g})$, cefazolin $(30 \mu \mathrm{g})$, and trimethoprim-sulfamethoxsazole $(1.25 / 23.75 \mu \mathrm{g})$, ampicillin $(5 \mu \mathrm{g})$, cefoxitin $(30 \mu \mathrm{g})$, novobiocin $(5 \mu \mathrm{g})$. Muller-Hinton agar plats were used for susceptibility tests and the bacterial concentrations for inoculation of plates were equal to $0.5 \mathrm{McF}$ arland. The disks were incubated with the inoculated plates at $37{ }^{\circ} \mathrm{C}$ overnight. Based on CLSI guideline, S. aureus ATCC 25923 (methicillin susceptible) and $S$ aureus ATCC 33591 (methicillin resistant) were used as positive control and ultrapure water was as negative control.

\section{Statistical analysis}

Statistical analysis was carried out by the SPSS version 16. Demographic and clinical variables were compared by Chi square test $(p<0.05)$.

\section{Results \\ Bacterial identification}

A total of 560 samples from nasal, throat and skin around the catheter were obtained from 231 hemodialysis patients. A total of $166 \mathrm{~S}$. aureus isolates (29.64\%) were isolated from 560 samples which $62.04 \%$ (103/166) of $S$. aureus isolates were MRSA. Totally, from 231 patients, 118 individuals $(50.65 \%)$ were identified as $S$. aureus carriage which $67.79 \%(80 / 118)$ of them were MRSA carriers. There was no significant difference in the prevalence of MRSA among hemodialysis patients with history of past illness. Demographic data of patients including gender, age, risk factors, illness history and the types of collected

Table 1 Demographic data of hemodialysis patients admitted to Imam Reza hospital of Tabriz

\begin{tabular}{|c|c|c|c|}
\hline Study group $(n=231)$ & MRSA & MSSA & $p$ value \\
\hline \multicolumn{4}{|l|}{ Gender } \\
\hline Female $(n=86)$ & 35 & 15 & 0.302 \\
\hline Male $(n=145)$ & 45 & 23 & \\
\hline \multicolumn{4}{|l|}{ Age } \\
\hline $17-30(n=21)$ & 2 & 7 & 0.0522 \\
\hline $31-40(n=15)$ & 6 & 2 & 0.35238 \\
\hline $41-50(n=27)$ & 10 & 8 & 0.846755 \\
\hline $51-60(n=56)$ & 20 & 11 & 0.891901 \\
\hline$>60(n=110)$ & 37 & 15 & 0.832589 \\
\hline \multicolumn{4}{|l|}{ Samples $(n=560)$} \\
\hline Nasal $(s=228)$ & 70 & 37 & $<0.00001$ \\
\hline Trout $(s=225)$ & 15 & 11 & \\
\hline Around catheter $(s=114)$ & 18 & 14 & \\
\hline \multicolumn{4}{|l|}{ Vascular access for dialysis } \\
\hline Catheter $(n=116)$ & 52 & 16 & $0.030,<0.05$ \\
\hline Fistula $(n=115)$ & 29 & 21 & \\
\hline \multicolumn{4}{|l|}{ Illness history } \\
\hline Hypertension ( $n=129)$ & 50 & 20 & 0.299 \\
\hline Diabetes mellitus $(n=102)$ & 31 & 18 & 0.399 \\
\hline Glomerulonephritis $(n=10)$ & 4 & 2 & 0.95 \\
\hline Polycystic kidney $(n=11)$ & 4 & 3 & 0.336 \\
\hline Pulmonary infections $(n=6)$ & 2 & 1 & 0.962 \\
\hline Cardiovascular $(n=22)$ & 9 & 3 & 0.555 \\
\hline Familial Mediterranean fever $(n=1)$ & 1 & 1 & 0.761 \\
\hline Lupus $(n=2)$ & 2 & 0 & 0.259 \\
\hline Length of hospitalization (27) & 11 & 6 & 0.627 \\
\hline Smoking (17) & 4 & 5 & 0.118 \\
\hline Antibiotic consumption $(n=34)$ & 14 & 5 & 0.562 \\
\hline
\end{tabular}

$\mathrm{n}$, number of patients; s, number of samples 
clinical specimens were summarized in Table 1. According to statistical analysis results, the frequency of MRSA is independent on gender $(p=0.302)$. But, it was dependent on sampling site so that prevalence of MRSA was significantly higher in nasal samples $(30.70 \%)(p<0.00001)$. $S$. aureus colonization in the absence of nasal colonization was observed in $12.71 \%$ (15/118) patients. Based on results, frequency of MRSA colonization was dependent on type of vascular access used in hemodialysis patients $(p=0.032)$ so that $44.06 \%$ of MRSA carriers were related to hemodialysis patients with a catheter.

\section{Antimicrobial susceptibility}

Antibiotic resistance profile to 11 antibiotics was determined on $166 \mathrm{~S}$. aureus isolates by the disc diffusion agar. The highest antibiotic resistance rate was observed against Ampicillin (93.98\%) and the highest sensitivity was against linezolid antibiotic disk (5.42\%). However, based on CLSI guideline, intermediate sensitivity values to linezolid was not reported. Based on results of resistance to cefoxitin, $34.93 \%(80 / 231)$ of patients were MRSA carriage. Details of results of the disc diffusion test are shown in Fig. 1. Out of the $166 \mathrm{~S}$. aureus isolates, 90 (54.22\%) isolates including 58 (34.94\%) nasal, 16 (9.64\%) catheter, 16 (9.64\%) throat showed multi-drug resistant property (MDR) based on resistance to three or more classes of antibiotic [8] and 2 isolates (1.2\%) were resistant to all of antibiotics.

\section{Discussion}

At present, increasing prevalence of MRSA infections has become a serious issue in clinical settings due to MRSAs are resistant to most of antibiotic classes especially $\beta$-lactams [9]. According to researches done, there is a direct relationship between $S$. aureus colonization and incidence of infection $[10,11]$. In the present study, $S$. aureus colonization was detected in $50.65 \%$ of hemodialysis patients that $67.79 \%$ of $S$. aureus isolates were found as MRSA and totally $34.93 \%$ of patients were identified as MRSA carriage. In a study conducted in north of Iran, $36.9 \%$ of hemodialysis patients were found as $S$ aureus carriage which MRSA colonization was detected in $74.2 \%$ of $S$. aureus carriers [12]. But, in a study carried out on hemodialysis patients in South of Iran, only $19.67 \%$ of individuals, were carriers of S. aureus and $6.56 \%$ were MRSA carriage [13]. The rate of $S$. aureus colonization at nasal, throat and catheter around was documented in $30.78 \%, 6.66 \%$ and $15.78 \%$ of hemodialysis patients while in one report offered from north of Iran, 36.9\% of hemodialysis patients were $S$. aureus nasal carriage [12].

Also, in another study carried out by Devraj et al. $S$. aureus colonization in throat were observed in $11.4 \%$ of hemodialysis patients [14].

In our study, $44.06 \%$ of MRSA carriers were related to hemodialysis patients using from a catheter. In this respect, researches showed that the possibility of infection in patients with catheter is two- to threefold higher than individuals with a fistula or graft [15].

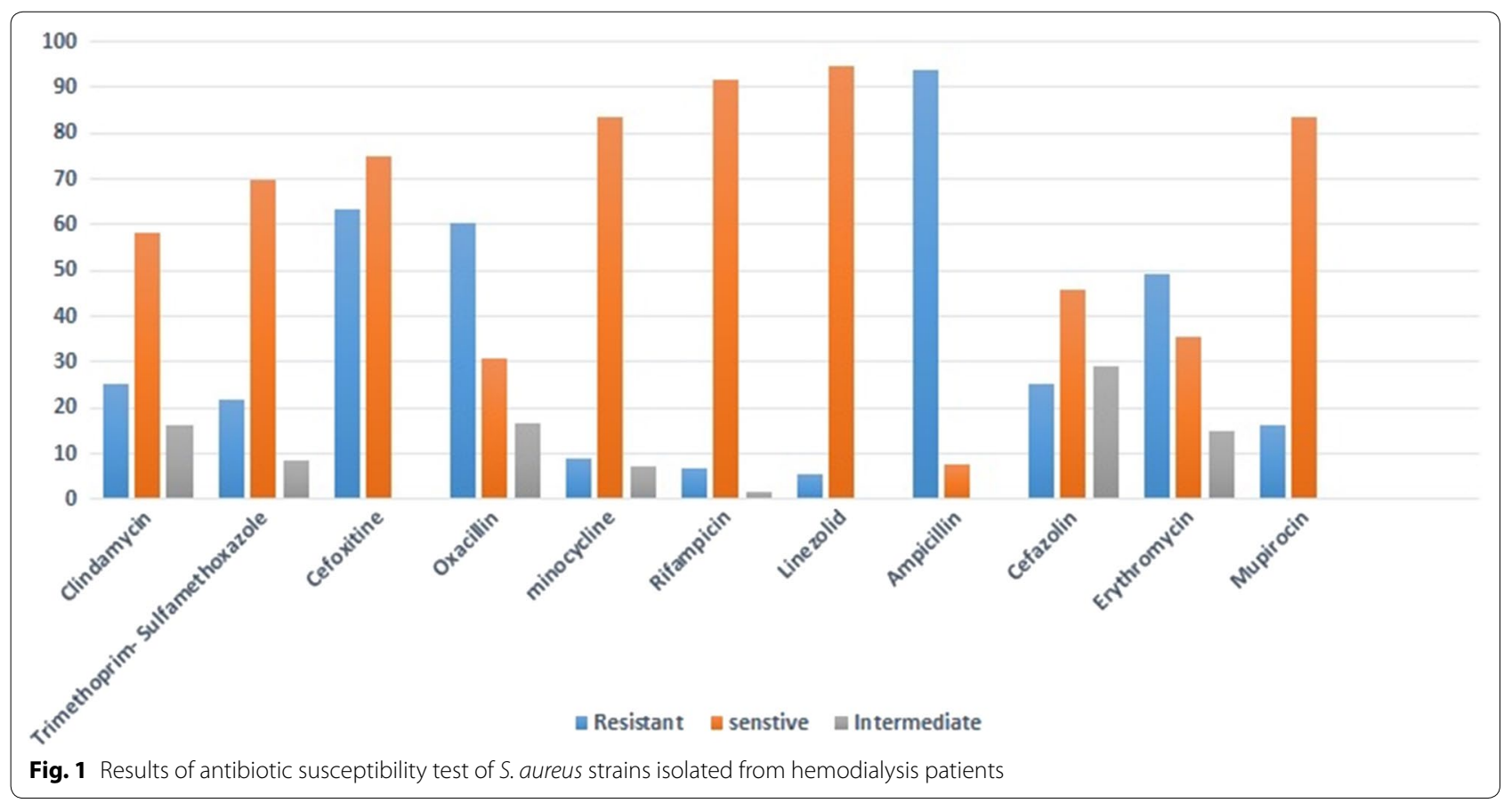


In the present study, $25 \%$ of $S$. aureus isolates were resistant to Clindamycin, consistent with results obtained from south of IRAN [13]. Also, $6.63 \%$ of $S$. aureus isolates were resistant to Rifampicin similar with study carried out in Mashhad, Iran [16].

In this study, there was no significant difference in the prevalence of MRSA colonization among hemodialysis patients with past illness history. These results were consistent with the similar results regarding lack of relationship between $S$. aureus colonization and clinical conditions of hemodialysis patients such as diabetes and Hypertension $[12,14]$. In the present study, MRSA colonization was independent of age consistent with similar studies $[17,18]$.

Although, S. aureus colonization is often detected in nasal, there are evidences regarding extra nasal $S$. aureus colonization in patients $[19,20]$. Our results are indicating incidence of $12.711 \%$ extranasal S. aureus colonization without nasal colonization in patients that is similar to results of Zahed et al. conducted in Tehran, Iran regarding incidence of $12 \%$ extranasal S. aureus colonization in hemodialysis patients [21].

\section{Conclusion}

Our results were indicating incidence of nasal and extranasal MRSA colonization in hemodialysis patients in the study region. These findings highlight the necessity of prophylaxis against $S$. aureus in individuals under dialysis.

\section{Limitations}

Since, the conventional biochemical tests are not definitive and can misidentify $S$. aureus isolates so PCR method can be used for confirmation of $S$. aureus and MRSA isolates.

\section{Abbreviations}

MRSA: methicillin resistant Staphylococcus (S.) aureus; TSS: toxic shock syndrome; MDR: multi-drug resistant.

\section{Acknowledgements}

This study was supported by Infectious and Tropical Diseases Research Center, Tabriz University of Medical Sciences, Tabriz, Iran.

\section{Authors' contributions}

FRG designed the study and collected samples. LR drafted the work and wrote the manuscript. BN interpreted data. $A D, A B$ and $M V$ were involved in study analysis. MHGA performed microbial and molecular tests. All authors read and approved the final manuscript.

\section{Funding}

This research received no specific grants from funding agency.

\section{Availability of data and materials}

All data generated or analyzed during this study are included in this published article.

\section{Ethics approval and consent to participate}

The study was conducted after ethical approval of the ethics committee of Tabriz University of medical science, Tabriz Iran (Reference Number: IR. TBZMED. REC.1397.448). Data and swab samples were collected after written consent with a brief description about the importance of the study to the participants.

\section{Consent for publication}

Not applicable.

\section{Competing interests}

The authors declare that they have no competing interests.

\section{Author details}

${ }^{1}$ Infectious and Tropical Diseases Research Center, Tabriz University of Medical Sciences, P.O.Box; 5163639888, Tabriz, Iran. ${ }^{2}$ Higher Education Institute of RabRashid, Tabriz, Iran, Tabriz, Iran. ${ }^{3}$ Biotechnology Department, East Azerbaijan Research and Education Canter Agricultural and Natural Resources, AREEO, Tabriz, Iran. ${ }^{4}$ Drug Applied Research Center, Tabriz University of Medical Sciences, Tabriz, Iran.

Received: 23 February 2019 Accepted: 3 May 2019

Published online: 10 May 2019

\section{References}

1. Lin YC, Peterson ML. New insights into the prevention of staphylococcal infections and toxic shock syndrome. Exp Rev Clin Pharmacol. 2010;3(6):753-67.

2. Fridkin SK, Hageman JC, Morrison M, Sanza LT, Como-Sabetti K, Jernigan JA, et al. Methicillin-resistant Staphylococcus aureus disease in three communities. N Engl J Med. 2005:352(14):1436-44.

3. Purrello SM, Garau J, Giamarellos E, Mazzei T, Pea F, Soriano A, et al. Methicillin-resistant Staphylococcus aureus infections: a review of the currently available treatment options. J Glob Antimicrob Resist. 2016;7:178-86.

4. Davoodabadi F, Mobasherizadeh S, Mostafavizadeh K, Shojaei H, Havaei SA, Koushki AM, et al. Nasal colonization in children with community acquired methicillin-resistant Staphylococcus aureus. Adv Biomed Res. 2016:5:86.

5. Pathak A, Marothi Y, lyer RV, Singh B, Sharma M, Eriksson B, et al. Nasal carriage and antimicrobial susceptibility of Staphylococcus aureus in healthy preschool children in Ujjain, India. BMC Pediatr. 2010;10(1):100.

6. Fooladi AAl, Ashrafi E, Tazandareh SG, Koosha RZ, Rad HS, Amin M, et al. The distribution of pathogenic and toxigenic genes among MRSA and MSSA clinical isolates. Microb Pathog. 2015:81:60-6.

7. Wayne PA. Performance standards for antimicrobial susceptibility testing. Wayne: Clinical and Laboratory Standards Institute; 2011.

8. Magiorakos A, Srinivasan A, Carey RB, Carmeli Y, Falagas ME, Giske CG, et al. Multidrug「ÇÉresistant, extensively drug「ÇÉresistant and pandrugГÇÉresistant bacteria: an international expert proposal for interim standard definitions for acquired resistance. Clin Microbiol Infect. 2012;18(3):268-81.

9. Fuda C, Suvorov M, Vakulenko SB, Mobashery S. The basis for resistance to $\beta$-lactam antibiotics by penicillin-binding protein 2a of methicillinresistant Staphylococcus aureus. J Biol Chem. 2004;279(39):40802-6.

10. Krishna VN, Allon M. What is the significance of Staphylococcus aureus colonization in hemodialysis patients? Nephron. 2015;129(2):75-8.

11. El Aila NA, Al Laham NA, Ayesh BM. Nasal carriage of methicillin resistant Staphylococcus aureus among health care workers at Al Shifa hospital in Gaza Strip. BMC Infect Dis. 2017;17(1):28.

12. Ghasemian R, Najafi N, Makhlough A, Khademloo M. Frequency of nasal carriage of Staphylococcus aureus and its antimicrobial resistance pattern in patients on hemodialysis. Iranian J Kidney Dis. 2010;4(3):218.

13. Tashakori M, Moghadam FM, Ziasheikholeslami N, Jafarpour P, Behsoun M, Hadavi M, et al. Staphylococcus aureus nasal carriage and patterns of antibiotic resistance in bacterial isolates from patients and staff in a dialysis center of southeast Iran. Iranian J Microbiol. 2014:6(2):79.

14. Jha V, Devraj A, Pinnamaneni VST, Biswal M, Ramachandran R. Extranasal S. aureus colonization predisposes to bloodstream infections in patients 
on hemodialysis with non-cuffed internal jugular vein catheters. Hemodial Int. 2016;21(1):35-40,

15. Eells SJ, Kalantar-Zadeh K, Bolaris MA, May L, Miller LG. Body site Staphylococcus aureus colonization among maintenance hemodialysis patients. Nephron. 2015;129(2):79-83.

16. Arianpoor A, Estaji F, Naderinasab M, Askari E. Antimicrobial susceptibility pattern of Staphylococcus aureus isolates against newly marketed antibiotics: a report from Imam Reza Hospital of Mashhad, Iran. Razavi Int J Med. 2015;3(4):e31568.

17. Silveira M, de Souza MDLR, Souza CSM, Correa AAF, Fortaleza CMCB. Nasal colonization with methicillin-resistant Staphylococcus aureus among elderly living in nursing homes in Brazil: risk factors and molecular epidemiology. Ann Clin Microbiol Antimicrob. 2018;17(1):18.

18. Mobasherizadeh S, Shojaei H, Havaei SA, Mostafavizadeh K, Davoodabadi F, Khorvash F, et al. Nasal carriage screening of community-associated methicillin resistant Staphylococcus aureus in healthy children of a developing country. Adv Biomed Res. 2016;5:144.
19. Patel G, Jenkins SG, Mediavilla JR, Kreiswirth BN, Radbill B, Salgado CD, et al. Clinical and molecular epidemiology of methicillin-resistant Staphylococcus aureus among patients in an ambulatory hemodialysis center. Infect Control Hosp Epidemiol. 2011;32(9):881-8.

20. Schmid H, Romanos A, Schiff H, Lederer SR. Persistent nasal methicillinresistant Staphylococcus aureus carriage in hemodialysis outpatients: a predictor of worse outcome. BMC Nephrol. 2013;14(1):93

21. Zahed NS, Aminzadeh Z, Mirab ASA, Gachkar L, Akhbari A. Nasal and extra-nasal methicillin resistant Staphylococcus aureus colonization among hemodialysis patients; is routine culturing of other body sites necessary? J Renal Injury Prev. 2018;7(4):280-5.

\section{Publisher's Note}

Springer Nature remains neutral with regard to jurisdictional claims in published maps and institutional affiliations.
Ready to submit your research? Choose BMC and benefit from:

- fast, convenient online submission

- thorough peer review by experienced researchers in your field

- rapid publication on acceptance

- support for research data, including large and complex data types

- gold Open Access which fosters wider collaboration and increased citations

- maximum visibility for your research: over 100M website views per year

At BMC, research is always in progress.

Learn more biomedcentral.com/submissions 